\title{
Penerapan Aplikasi Akuntansi Pendapatan Sewa Ruang Pada Klub Eksekutif Persada
}

\author{
Vivi Maria*)1), Rusma Insan Nurachim²) \\ ${ }^{12)}$ Program Studi Sistem Informasi Akuntansi, Universitas Bina Sarana Informatika \\ ${ }^{*}$ Correspondence author: vivi.vvm@ bsi.ac.id, DKI Jakarta, Indonesia
}

\begin{abstract}
Abstrak
Memasuki dunia bisnis saat ini dibutuhkan keterampilan dari pengusaha dalam mengelola sistem informasi dan keuangan. Klub Eksekutif Persada memerlukan pengelolaan penerimaan kas yang diterima dari pendapatan sewa. Dengan menggunakan program penerimaan kas dari penyewaan ruangan ini didapatkan solusi yang terbaik untuk memecahkan permasalahan-permasalahan yang ada pada perusahaan ini. Program juga dapat membantu tercapainya efektifitas dan efisiensi dalam aktifitas Klub Eksekutif Persada. Dari hasil penelitian dapat disimpulkan bahwa pemrosesan penerimaan kas dari penyewaan lebih cepat dan akurat jika menggunakan aplikasi berbasis komputer.
\end{abstract}

Kata Kunci: Penyewaan, Aplikasi, Penerimaan Kas

\begin{abstract}
Entering the business world today requires skills from entrepreneurs in managing information and financial systems. The Persada Executive Club requires the management of cash receipts received from rental income. By using the cash receipts program from renting the room, the best solution is to solve the problems that exist in this company. The program can also help achieve effectiveness and efficiency in the activities of the Persada Executive Club. From the results of the study it can be concluded that the processing of cash receipts from leasing is faster and more accurate when using computer-based applications.
\end{abstract}

Keywords: Information Systems, Inventory, Medicine Supply

\section{PENDAHULUAN}

Memasuki dunia bisnis saat ini yang dibutuhkan keterampilan dari seorang pengusaha dalam mengelola sistem informasi dan keuangan. Dengan menggunakan teknologi seperti komputer sangat membantu kegiatan operasional perusahaan seperti di dalam dunia perbankan, perkantoran, perdagangan dan penyewaan. Pada dasarnya komputer dibuat untuk membantu manusia dalam menyelesaikan persoalan yang dihadapi. Namun untuk menyelesaikan suatu persoalan dengan menggunakan komputer manusia perlu mengikuti aturan yang dimengerti oleh komputer. Konsep dasar program memegang peranan penting dalam merancang, menyusun, memelihara serta mengembangkan suatu program. Pembuatan program tentunya tidak terlepas dari tahapan-tahapan yang harus dikerjakan secara terstruktur untuk membantu programmer dalam menyelesaikan programnya dengan baik. (Wasiyanti, 2018) 
Maksud dari penelitian ini adalah, membantu proses penerimaan kas dengan suatu sistem yang telah terkomputerisasi, agar dapat memudahkan dalam memperoleh data-data yang akurat dan dapat menyajikan laporan dengan cepat. Memberikan alternatif solusi untuk memperbaiki permasalahan yang terjadi pada sistem penerimaan kas agar lebih efektif dan efisien dengan dukungan teknologi komputer. Meminimalisasi tingkat kesalahan dalam pembuatan laporan penerimaan kas dari penyewaan ruang. (Romy Budhi Widodo, 2007) "Sistem Informasi Akuntansi (SIA) merupakan sistem informasi yang melaksanakan aplikasi akuntansi perusahaan, yaitu sebagai pengolah data perusahaan. Perusahaan tidak dapat memilih untuk menggunakan SIA atau tidak, sistem ini merupakan keharusan. Semua perusahaan pada dasarnya melaksanakan prosedur-prosedur yang sama. SIA lebih berorientasi pada data dibanding pada informasi, walaupun ada beberapa informasi yang dihasilkan. SIA menyediakan database bagi sistem informasi lainnya." (Mulyadi, 2008) "Pendapatan adalah penghasilan yang timbul dari aktivitas perusahaan biasa dan dikenal dengan sebutan berbeda seperti penjualan, penghasilan jasa, bunga, royalti dan sewa." Pendapatan harus diukur dengan nilai wajar imbalan yang diterima atau yang dapat diterima. Pada umumnya imbalan tersebut berbentuk kas dan setara kas.” (Mulyadi, 2008) "Jasa adalah setiap kegiatan atau manfaat yang ditawarkan oleh suatu pihak pada pihak lain dan pada dasarnya tidak berwujud, serta tidak menghasilkan kepemilikan sesuatu." (Mulyadi, 2008)

Sewa menyewa adalah suatu perjanjian, dengan mana pihak yang satu mengikatkan dirinya untuk memberikan kenikmatan suatu barang kepada pihak lain selama waktu tertentu, dengan pembayaran suatu harga yang disanggupi oleh pihak yang terakhir itu." (Mulyadi, 2008)

"Program dapat diartikan sebagai suatu kumpulan langkah-langkah atau rangkaian instruksi-instruksi atau tahapan-tahapan pengolahan yang ditulis dalam bahasa pemrograman yang disusun secara logis dan sistematis yang telah dipersiapkan agar komputer dapat melakukan fungsinya dengan cara yang telah ditentukan”. (Budi, 2010)

"Microsoft Visual Basic 6.0 adalah software untuk membuat program berbasis windows". Visual Basic 6.0 menggunakan bahasa pemrograman Beginners All Purpose Symbolic Instruction Code (BASIC) yang merupakan salah satu bahasa pemrograman tingkat tinggi yang sederhana dan mudah untuk dipelajari. Istilah visual mengacu pada metode pembuatan tampilan program (interface) atau objek pemrograman yang biasa dilakukan secara langsung terlihat oleh programmer. Dalam Visual Basic, pembuatan program aplikasi harus dikerjakan dalam sebuah project. Sebuah project dapat terdiri dari file 
project(.vbp),file form (.frm), file data binary (.frx), modul class (.cls), modul standar (.bas), dan file resource tunggal (.res).” (Budi, 2010)

"Database merupakan suatu bentuk pengelolaan data yang ditujukan agar pengaksesan terhadap data dapat dilakukan dengan mudah". (Kadir, 2005)

"Normalisasi merupakan salah satu pendekatan atau teknik yang digunakan dalam membangun disain lojik basis data relational dengan menerapkan sejumlah aturan dan kriteria standar. Tujuan dari normalisasi adalah untuk menghasilkan struktur tabel yang normal atau baik". (Yakub, 2012)

"Bagan alir (flowchart) adalah bagan yang menggambarkan urutan intruksi proses dan hubungan satu proses dengan proses lainnya menggunakan simbol-simbol tertentu". (Budi, 2010)

"Spesifikasi File dibuat sebagai pendukung agar pemakai (user) program mengetahui segala yang berhubungan dengan file ataupun field name pada pengolahan database. Untuk itu dalam perancangan program penyewaan ini dibutuhkan beberapa file pendukung". (Ladjamudin, 2013)

"Struktur kode adalah mengklasifikasikan data, memasukkan data ke dalam komputer dan untuk mengambil bermacam-macam informasi yang berhubungan dengannya". (Jogiyanto, 2005)

\section{METODE}

Metode pengumpulan data yang digunakan yaitu: metode observasi, metode wawancara dan metode studi pustaka. Metodologi pengembangan sistem perangkat lunak yang digunakan adalah model Waterfall. "Model Waterfall adalah model yang menyediakan pendekatan alur hidup perangkat lunak secara sekuensial atau terurut dimulai dari analisis, desain, pengodean, pengujian dan tahap pendukung”. (Sukamto, 2013)

\section{HASIL DAN PEMBAHASAN}

Pendapatan sewa adalah penghasilan yang timbul dari aktivitas perusahaan biasa dan dikenal dengan sebutan berbeda seperti penjualan, penghasilan jasa, bunga, royalti dan sewa. Pendapatan harus diukur dengan nilai wajar imbalan yang diterima atau yang dapat diterima. Pada umumnya imbalan tersebut berbentuk kas dan setara kas. 


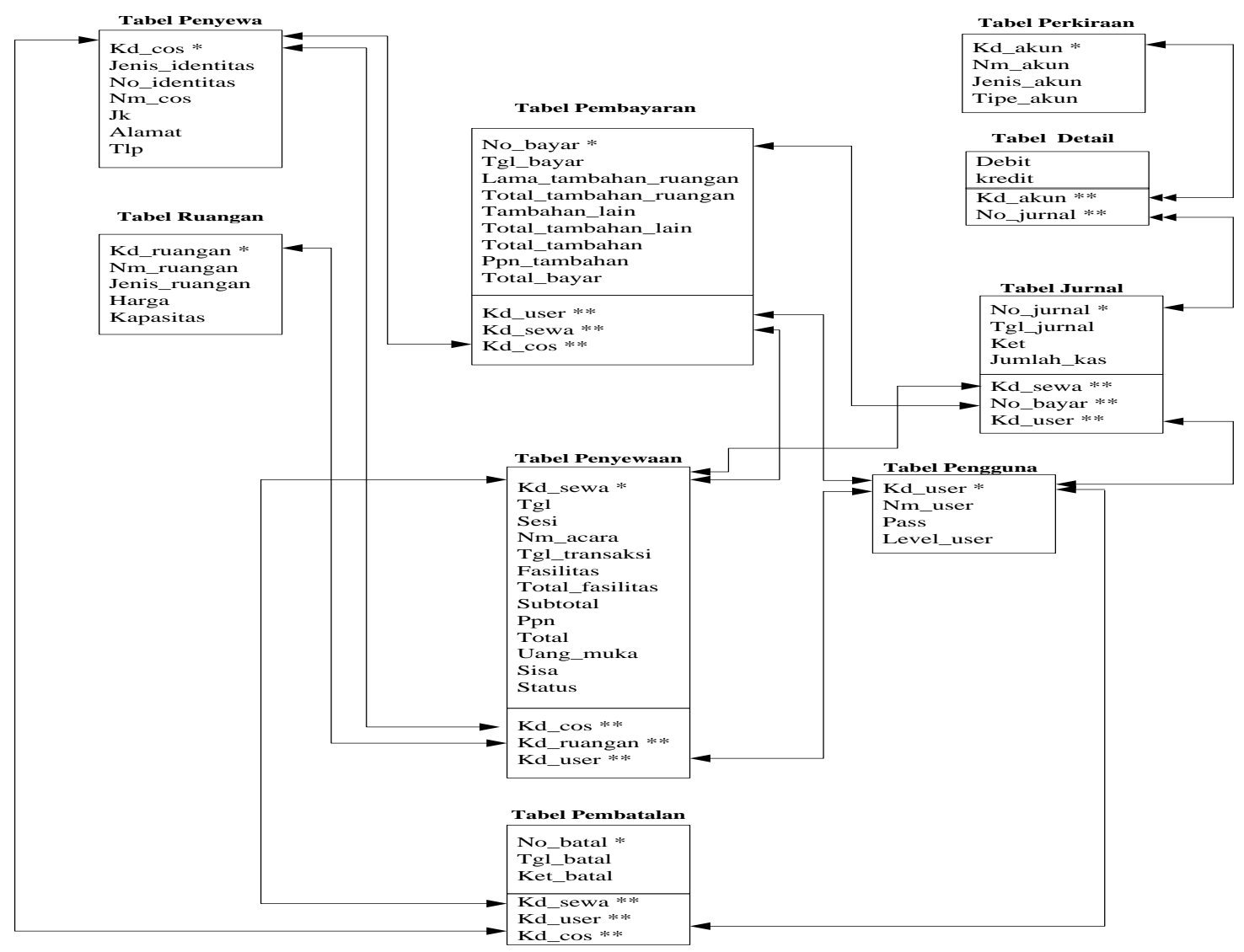

Gambar 1. Normalisasi 3NF Hasil Peneitian (2018)

Keterangan :

$$
\begin{array}{ll}
* & : \text { Primary Key } \\
* * & : \text { Foreign Key }
\end{array}
$$$$
\text { : one to one }
$$$$
\text { :one to many }
$$ 


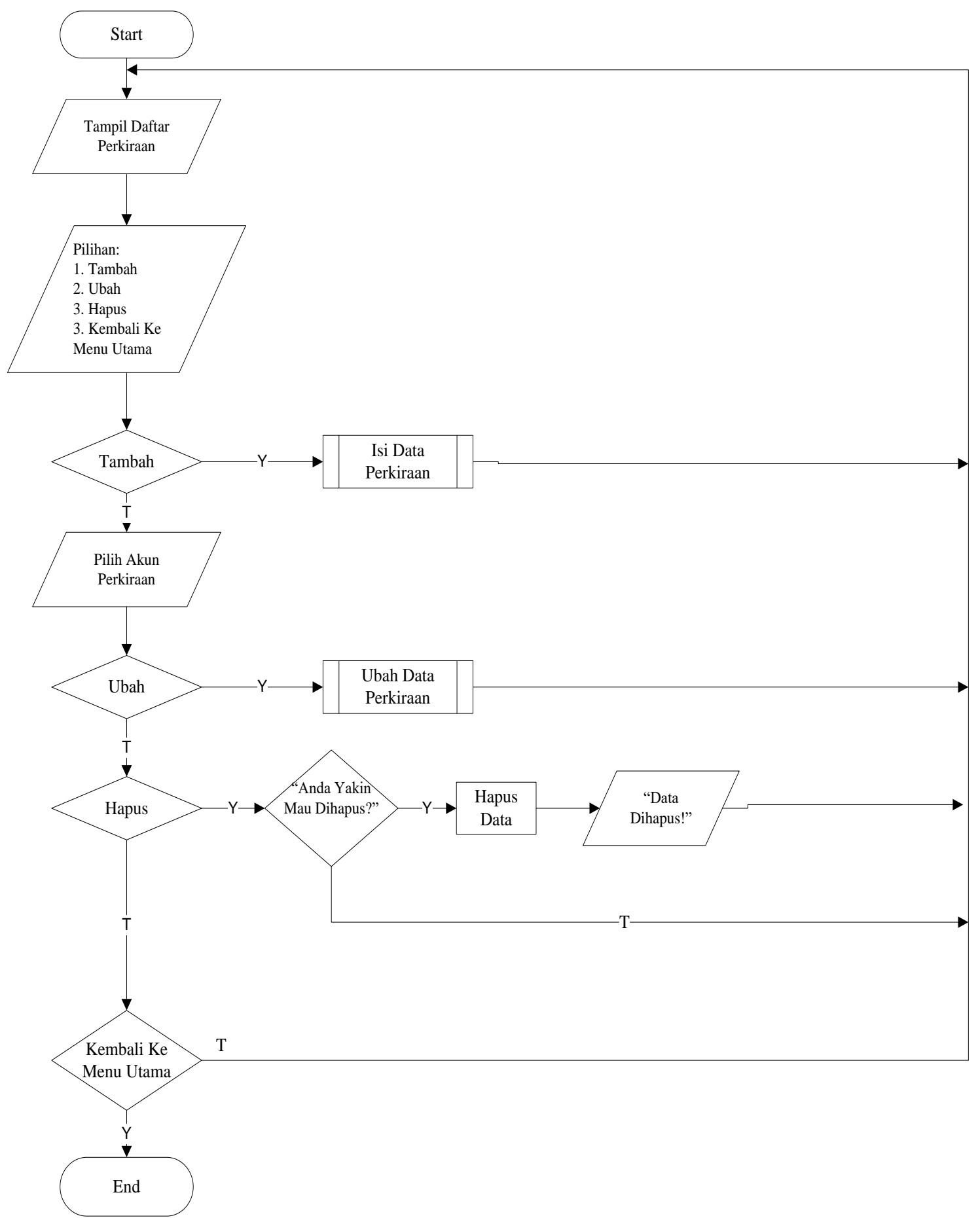

Gambar 2. Flowchart

Sumber : Hasil Penelitian (2018) 


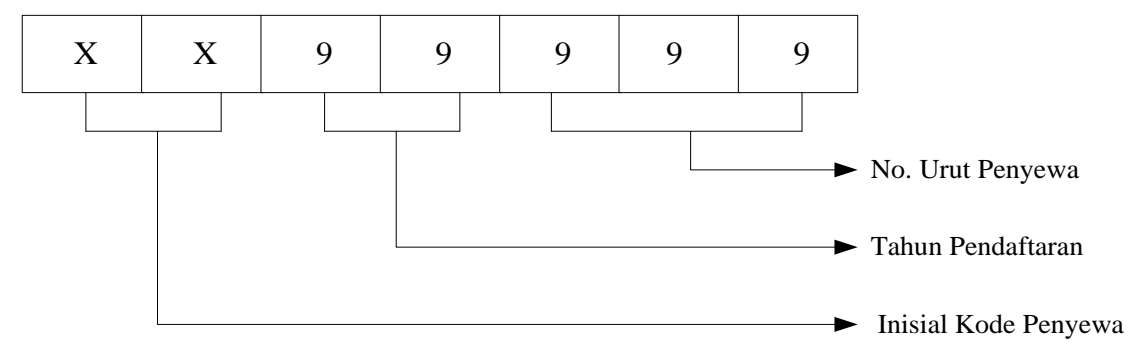

Contoh :

\begin{tabular}{|l|l|l|l|l|l|l|}
\hline $\mathrm{P}$ & $\mathrm{C}$ & 1 & 5 & 0 & 0 & 1 \\
\hline
\end{tabular}

Gambar 3. Pengkodean

Sumber : Hasil Penelitian(2018)

Keterangan:

PC adalah inisial kode penyewa (Persada Costumer), 15 adalah dua digit terakhir dari tahun pendaftaran penyewa dan 001 adalah nomor urut penyewa.

Bentuk dokumen masukan merupakan dokumen atau data yang dipakai sebagai acuan untuk pembuatan dan mengisi data pada program aplikasi yang dibuat. Sedangkan rancangan bentuk keluaran adalah perincian tentang dokumen keluaran yang merupakan hasil dari program atau sistem yang berjalan.

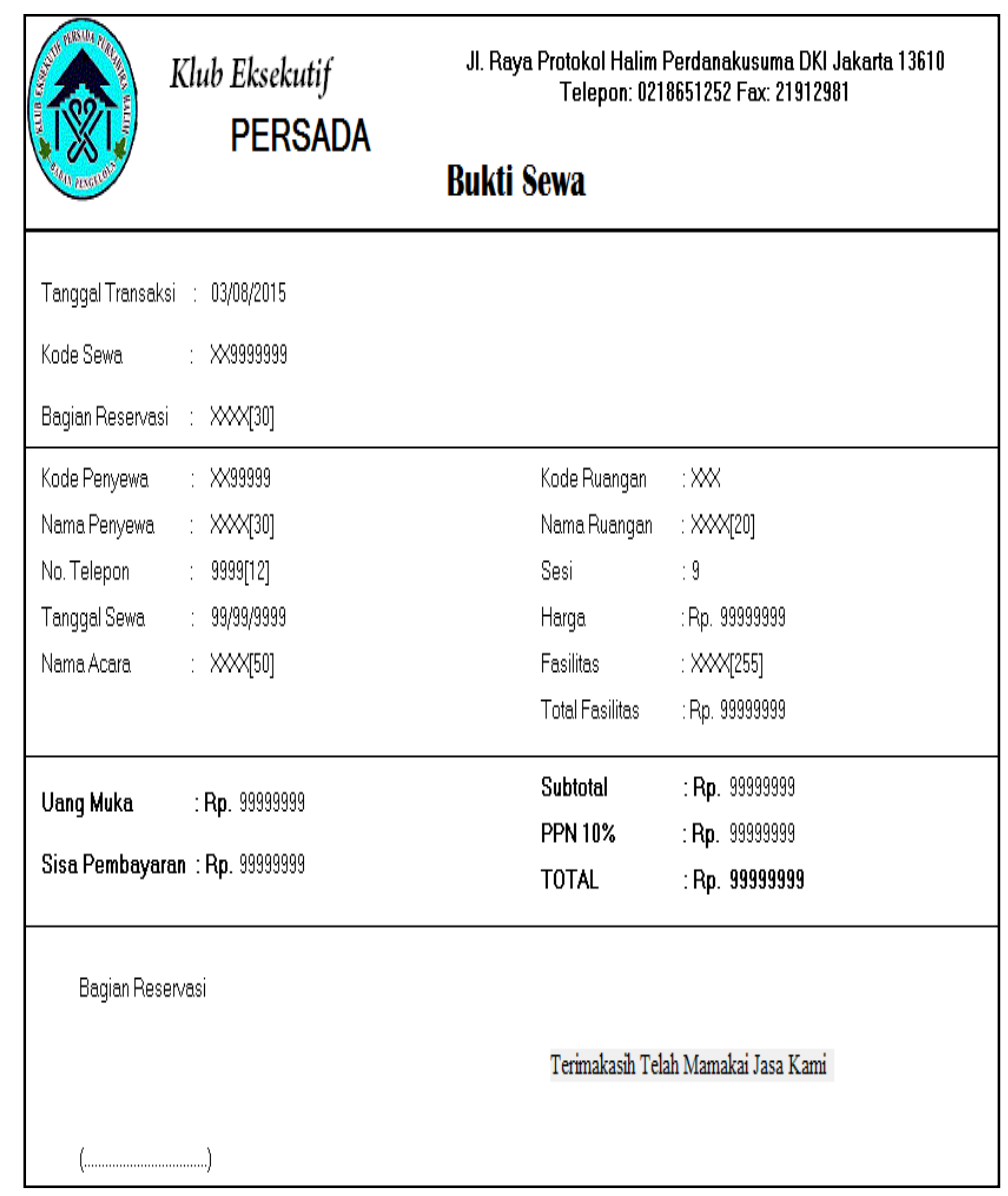

Gambar 4. Rancangan Dokumen

Sumber: Hasil Penelitian (2018) 


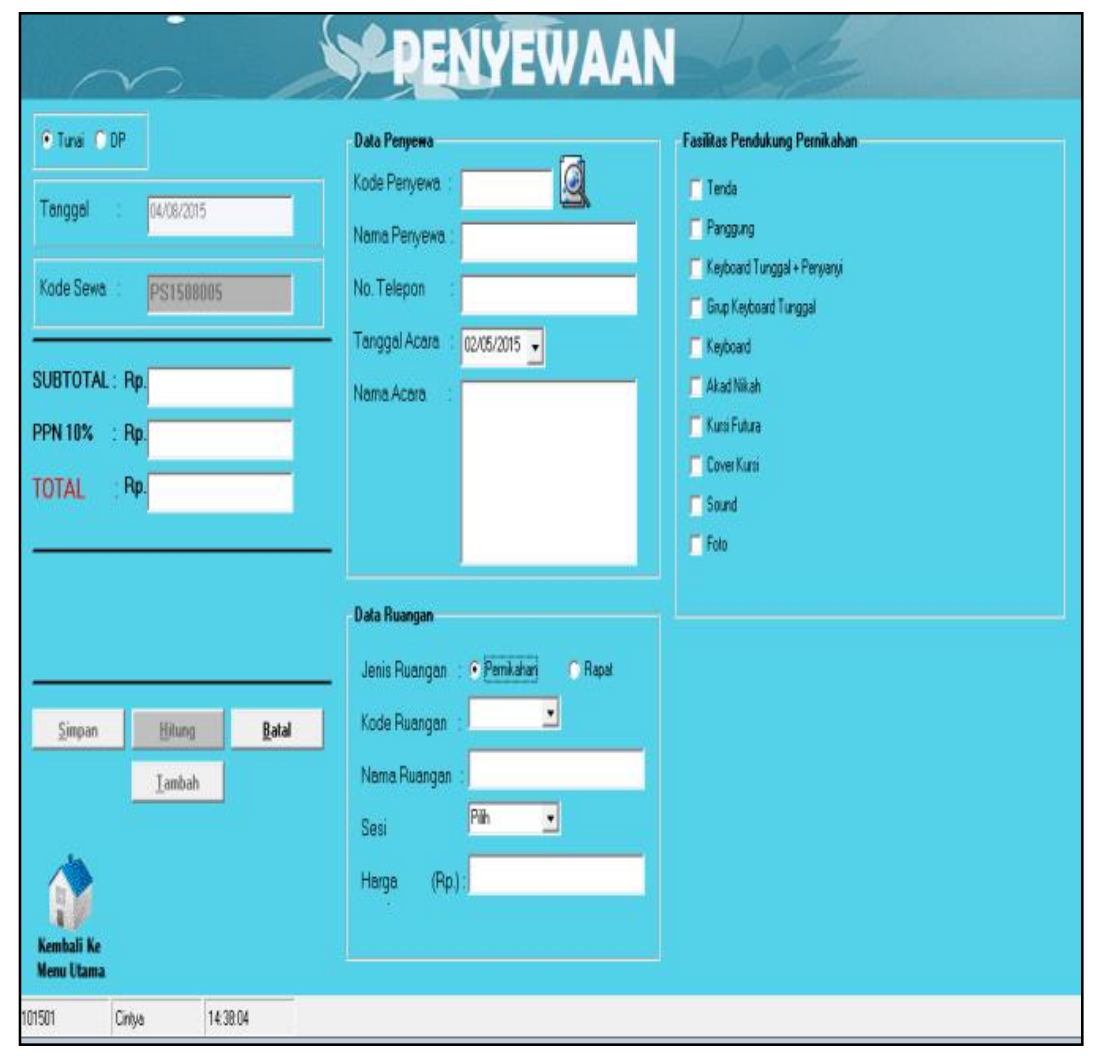

Gambar 5. Penyewaan

Sumber: Hasil Penelitian (2018)

\section{KESIMPULAN DAN REKOMENDASI}

Dari hasil penelitian dapat disimpulkan bahwa pengelolaan penerimaan kas dari penyewaan lebih cepat dan akurat jika menggunakan aplikasi berbasis computer. Proses kerja yang sudah terkomputerisasi tersebut dapat membantu lancarnya pelaksanaan kerja, terutama dalam penyajian informasi yang cepat, tepat dan akurat dalam laporan kas masuk. Data-data kegiatan administrasi usaha ini disimpan didalam sebuah sistem yang sudah terkomputerisasi guna kemanan, keefisienan, efektifitas waktu dan tempat.

Rekomendasi yang diberikan adalah, perlu kerjasama, kedisiplinan, dan ketelitian kerja personil dalam kelangsungan kerja sistem agar tidak terjadi kerusakan data dan sistem pada komputer. Proses back up atau perlindungan terhadap data-data merupakan hal yang sangat penting guna melindungi hilangnya data atau rusaknya data secara tiba-tiba yang disengaja atau tidak sehingga proses ini sebaiknya dilakukan secara berkala.

\section{REFERENSI}

Budi, R. (2010). Programming With Microsoft Visual Basic 6.0. . Malang: PT. Skripta Media Creative.

Jogiyanto, H. (2005). Analisis Dan Desain Sistem Informasi. Yogyakarta: Andi Offset. 
Kadir, A. (2005). Pemrograman Database Dengan Delphi 7 Menggunakan Access Dan ADO. Yogyakarta: Andi Offset.

Ladjamudin. (2013). Analisis dan Desain Sistem Informasi. Yogyakarta: Graha IImu.

Mulyadi. (2008). Sistem Akuntansi. Jakarta: Selemba Empat.

Romy Budhi Widodo, J. D. (2007). Interfacing Paralel dan Serial Menggunakan Delphi. Yogyakarta: Graha Ilmu.

Sukamto, R. A. (2013). Rekayasa Perangkat Lunak Terstruktur dan Berorientasi Objek. Bandung: Informatika.

Wasiyanti, S. (2018). Akuntansi Berbasis Aplikasi. Jakarta: Bina Sarana Informatika.

Yakub. (2012). Pengantar Sistem Informasi. Yogyakarta: Graha IImu. 